\title{
Preparation and Hydrolysis of Poly(2-Benzoyloxyethyl Vinyl Ether) with a Narrow Molecular Weight Distribution
}

\author{
Naotake Ogawa, ${ }^{*}$ Hiroyuki Taguchi, Yoshihiro Honda, and Takatoshi Sato \\ College of Pharmacy, Nihon University, 7-7-1 Narashinodai, Funabashi-shi, Chiba 274-8555, Japan. \\ Received September 17, 1997; accepted December 10, 1997
}

\begin{abstract}
2-Benzoyloxyethy vinyl ether (BOEVE) was cationically polymerized with the hydrogen iodide/zinc iodide $\left(\mathrm{HI} / \mathrm{ZnI}_{2}\right)$ initiating system in toluene at $-15^{\circ} \mathrm{C}$ to form a narrow molecular weight distribution (MWD). The poly(BOEVE) obtained had a narrow $\operatorname{MWD}\left(M_{w} / M_{n}<1.2, M_{w}\right.$ : weight-average molecular weight, $M_{n}$ : number-average molecular weight). The $M_{n}$ of the poly(BOEVE) increased directly in proportion to the BOEVE conversion and to the reciprocal of the initial HI concentration, that is, the reaction was found to be a living polymerization. The hydrolysis rate of the polymer in the alkaline dioxane-water system decreased with increase in the $M_{n}$ of the polymer.
\end{abstract}

Key words 2-benzoyloxyethyl vinyl ether; living polymerization; cationic polymerization; hydrolysis

Applications of functional polymers to medical and pharmaceutical fields are increasing year after year. Their use as chemical carriers of bioactive agents serves to decrease the toxicity of the agents and to increase polymer therapeutic efficiency. SMANCS, ${ }^{1)}$ a partially esterified poly[styrene-alt-(maleic anhydride)] (SMA) conjugated with the antitumor protein neocarzinostatin (NCS) has been used successfully as a polymeric drug with an increased stability to hydrolysis in blood. In addition, poly(ethylene glycol)-block-poly(aspartic acid) conjugated with adriamycin, ${ }^{2)}$ poly(malic acid) conjugated with 5-fluorouracil, ${ }^{3)}$ and others have been studied.

Since the properties of the polymer are affected by the number-average molecular weight $\left(\mathrm{M}_{\mathrm{n}}\right)$, the molecular weight distribution (MWD), and the chemical structure, it is assumed that a polymer with the desired properties can be obtained by controlling these aspects. In particular, the technique used to obtain a polymer which has a highly controlled $\mathrm{M}_{\mathrm{n}}$ and a narrow MWD is living polymerization. After Higashimura and co-workers discovered the possibility of living cationic polymerization, ${ }^{4}$ living polymers with various functional groups were obtained. ${ }^{5}$ )

In this report, living cationic polymerization of the 2-benzoyloxyethyl vinyl ether (BOEVE) by the hydrogen iodide/zinc iodide $\left(\mathrm{HI} / \mathrm{ZnI}_{2}\right)$ initiating system was studied. To elucidate the fundamental properties of the polymer obtained, the alkaline hydrolysis of the polymer was performed.

\section{Results and Discussion}

Preparation of the Poly(BOEVE) by Cationic Polymerization To obtain a polymer with a narrow MWD, it is desirable that side reactions (such as chain transfer, and termination) not be included in the polymerization. Living polymerization seems to be the most efficient technique to obtain such a polymer. Binary initiating systems ( $\mathrm{HI} /$ iodine $\left(\mathrm{I}_{2}\right)$ and $\left.\mathrm{HI} / \mathrm{ZnI}_{2}\right)$ which consist of $\mathrm{HI}$ and a weak Lewis acid $\left(\mathrm{I}_{2}\right.$ or $\left.\mathrm{ZnI}_{2}\right)$ are expected to permit living cationic polymerization of vinyl ethers. ${ }^{6,7)}$ The $\mathrm{HI} / \mathrm{ZnI}_{2}$ system was applied to BOEVE and the possibility of living cationic polymerization was examined.

In living polymerization (Chart 1), hydrogen iodide

* To whom correspondence should be addressed. quantitatively adds to the vinyl monomers to form adducts A which, as the initiating species, start living propagation via electrophilic activation of their carbon-iodine bonds with $\mathrm{I}_{2}$ or $\mathrm{ZnI}_{2}$ as the activators.

Figure 1 shows the time course of the polymerization with the $\mathrm{HI} / \mathrm{ZnI}_{2}$ and $\mathrm{HI} / \mathrm{I}_{2}$ initiating system. The polymerization with these systems proceeded without an induction period up to $100 \%$ conversion, and the polymerization rate quickened with increase of the initial concentration of $\mathrm{HI}, \mathrm{ZnI}_{2}$ or $\mathrm{I}_{2}$. The polymerization rate of the $\mathrm{HI} / \mathrm{ZnI}_{2}$ initiating system was faster than that of the $\mathrm{HI} / \mathrm{I}_{2}$ system in spite of the concentration of $\mathrm{ZnI}_{2}$ being smaller than that of $\mathrm{I}_{2}$. In the $\mathrm{HI} / \mathrm{I}_{2}$ initiating system, the concentration of $\mathrm{I}_{2}$ required to give the same rate as the $\mathrm{HI} / \mathrm{ZnI}_{2}$ initiating system was approximately 20 times that of $\mathrm{ZnI}_{2}$. In contrast, polymerization in the presence of $\mathrm{ZnI}_{2}$ alone did not give a polymer and in the presence of $\mathrm{HI}$ alone only the addition of $\mathrm{HI}$ to BOEVE occurred. Since the $\mathrm{ZnI}_{2}$ has high activities, the polymerization in

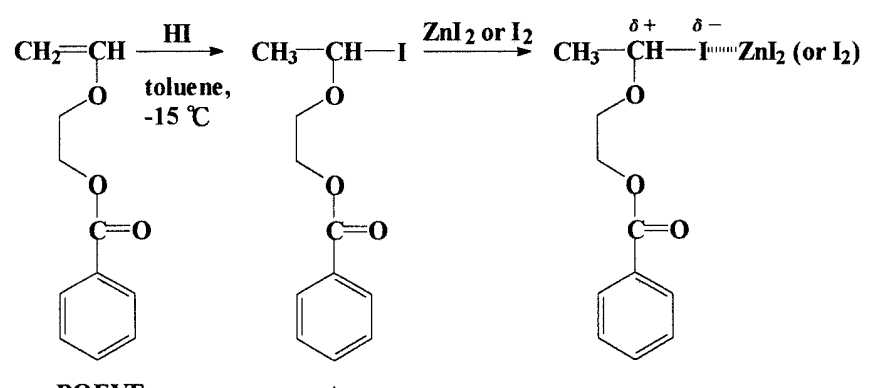

BOEVE

A

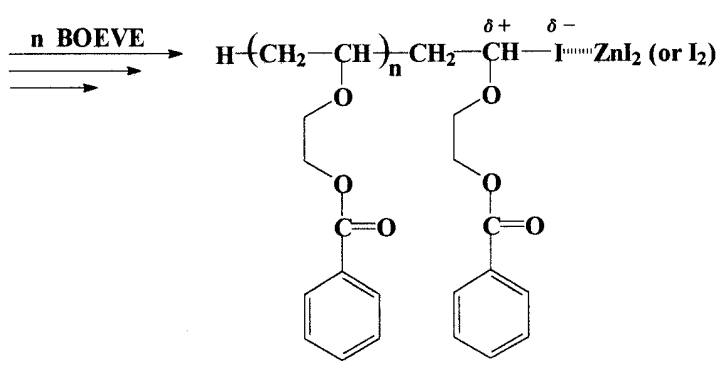

poly(BOEVE)

Chart 1

(C) 1998 Pharmaceutical Society of Japan 


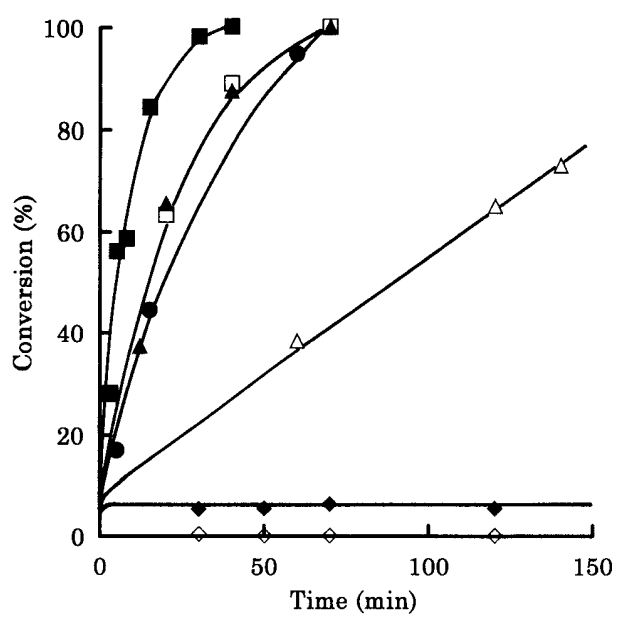

Fig. 1. Time-Conversion Plots for the Polymerization of BOEVE in Toluene at $-15^{\circ} \mathrm{C}$ with the $\mathrm{HI} / \mathrm{ZnI}_{2}$ Initiating System

$[\mathrm{BOEVE}]_{0}=0.18 \mathrm{M} . \square,[\mathrm{HI}]_{0}=15 \mathrm{mM} ;\left[\mathrm{ZnI}_{2}\right]=1 \mathrm{~mm} . \bullet,[\mathrm{HI}]_{0}=7 \mathrm{~mm}$ $\left[\mathrm{ZnI}_{2}\right]=1 \mathrm{mM} . \boldsymbol{\Delta},[\mathrm{HI}]_{0}=15 \mathrm{mM} ;\left[\mathrm{ZnI}_{2}\right]=0.5 \mathrm{~mm} . \diamond,[\mathrm{HI}]_{0}=15 \mathrm{mM} ;\left[\mathrm{ZnI}{ }_{2}\right]=$ none. $\diamond,[\mathrm{HI}]_{0}=$ none; $\left[\mathrm{ZnI}_{2}\right]=0.5 \mathrm{mM} . \square,[\mathrm{HI}]_{0}=15 \mathrm{~mm} ;\left[\mathrm{I}_{2}\right]=10 \mathrm{mM} . \triangle$ $[\mathrm{HI}]_{0}=15 \mathrm{~mm} ;\left[\mathrm{I}_{2}\right]=5 \mathrm{mM}$

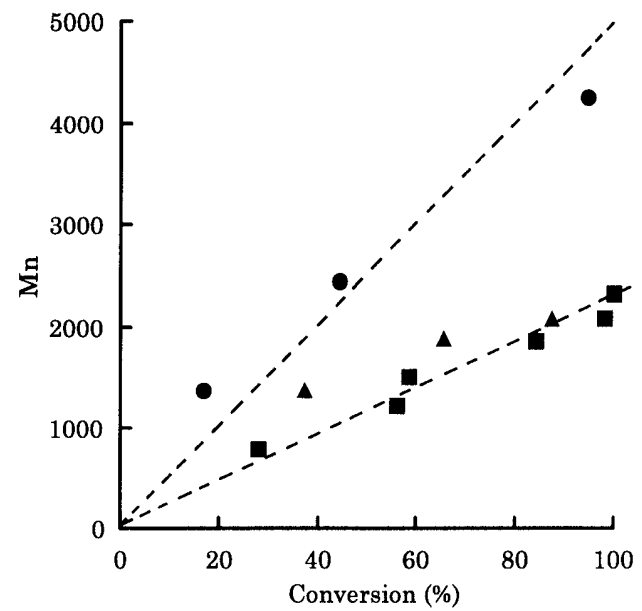

Fig. 2. Relationship between $M_{n}$ and Conversion on the Cationic Polymerization of BOEVE in Toluene at $-15^{\circ} \mathrm{C}$ with the $\mathrm{HI} / \mathrm{ZnI}_{2}$ Initiating System

$[B O E V E]_{0}=0.18 \mathrm{M} . \mathbf{\square},[\mathrm{HI}]_{0}=15 \mathrm{mM} ;\left[\mathrm{ZnI}_{2}\right]=1 \mathrm{~mm}$. $\left[\mathrm{ZnI}_{2}\right]=1 \mathrm{mM} . \mathbf{\Lambda},[\mathrm{HI}]_{0}=15 \mathrm{~mm} ;\left[\mathrm{ZnI}_{2}\right]=0.5 \mathrm{mM}$

the $\mathrm{HI} / \mathrm{ZnI}_{2}$ initiating system was further investigated.

Figure 2 shows the relationship between the $M_{n}$ and the conversion for the poly(BOEVE) in the $\mathrm{HI} / \mathrm{ZnI}_{2}$ initiating system shown in Fig. 1. The $M_{n}$ of the polymers was proportional to the conversion of BOEVE, dependent on the initial $\mathrm{HI}$ concentration, and almost agreed with the calculated $M_{n}$ for a living polymer (the broken line; $\mathrm{M} \times[\mathrm{BOEVE}]_{0} /[\mathrm{HI}]_{0} \times$ conversion, where $\mathrm{M}$ is the molecular weight of BOEVE, and $[\mathrm{BOEVE}]_{0}$ and $[\mathrm{HI}]_{0}$ are the initial concentration of BOEVE and $\mathrm{HI}$, respectively). HI seems to induce a quantitative initiation reaction to form the living polymer, while $\mathrm{ZnI}_{2}$ accelerates their propagation. Furthermore, the living nature of the polymerization was studied by a so-called "monomer addition" experiment where fresh feed of BOEVE was added to completely converted reaction mixtures (Fig. 3). This second-stage polymerization was also quantitative. The MWD of the polymers was very narrow $\left(M_{w} / M_{n} \leqq 1.1\right)$ over the whole conversion range and shifted towards a

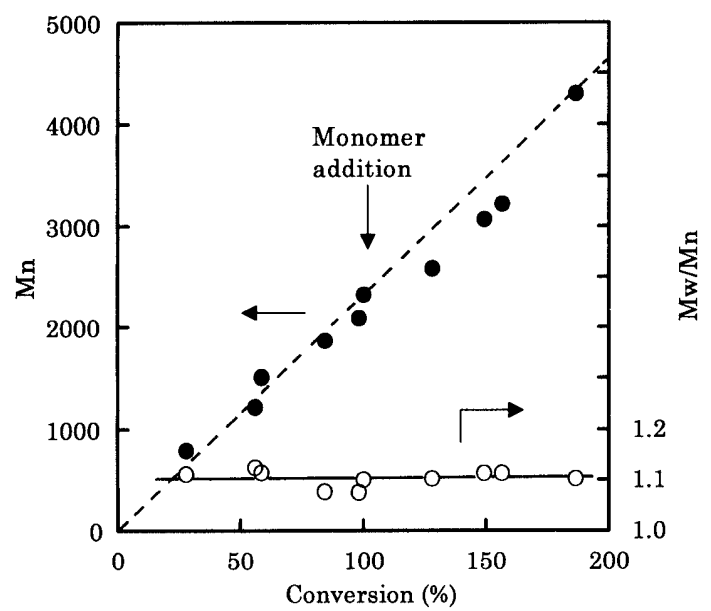

Fig. 3. $M_{n}$ and Its $M_{w} / M_{n}$ Values of Poly(BOEVE) Obtained in a Monomer-Addition Experiment with the Cationic Polymerization by the $\mathrm{HI} / \mathrm{ZnI}_{2}$ Initiating System in Toluene at $-15^{\circ} \mathrm{C}$

$[\mathrm{BOEVE}]_{0}=0.18 \mathrm{M} ;[\mathrm{HI}]_{0}=15 \mathrm{~mm} ;\left[\mathrm{ZnI}_{2}\right]=1 \mathrm{~mm}$.

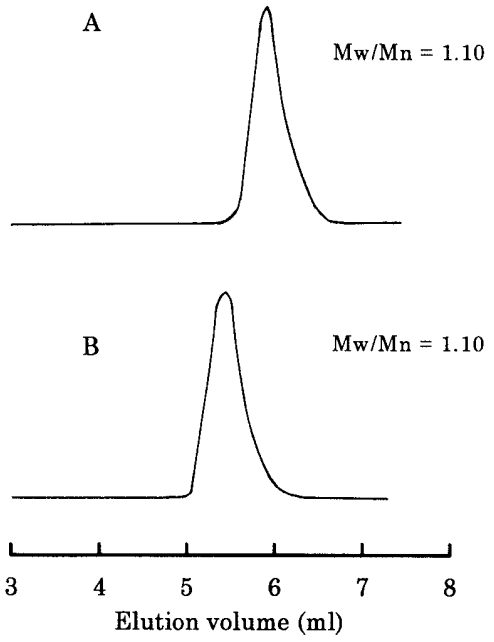

Fig. 4. Chromatogram of the Poly(BOEVE) Shown in Fig. 3

A, conversion $=100 \%$; , conversion $=200 \%$.

higher $M_{n}$ with the increasing conversion of BOEVE, regardless the quantity of $\mathrm{BOEVE}$ added. Chromatograms of the polymers at $100 \%$ and $200 \%$ conversion are shown in Fig. 4.

Figure 5 shows the effect of the $M_{n}$ and the MWD of the polymer at different feed ratios of the BOEVE to HI. When the BOEVE concentration was kept constant and $[\mathrm{HI}]_{0}$ varied from 0.8 to $15 \mathrm{~mm}$, the $\mathrm{M}_{\mathrm{n}}$ of the polymer after complete conversion of the BOEVE was definitely proportional to the reciprocal of $[\mathrm{HI}]_{0}$ and the narrow MWD of the polymers was maintained $\left(M_{w} / M_{n}<1.2\right)$.

Consequently, from the cationic polymerization of the BOEVE by the $\mathrm{HI} / \mathrm{ZnI}_{2}$ initiation system, a living polymer was obtained in a similar manner to that of BOEVE by the $\mathrm{HI} / \mathrm{I}_{2}$ system studied by Higashimura and coworkers, ${ }^{5,8)}$ and the poly(BOEVE) with a narrow MWD could be obtained.

Hydrolysis of Poly(BOEVE) Hydrolysis of the poly(BOEVE) with a narrow MWD obtained by living cationic polymerization was examined in dioxane-water media with $\mathrm{NaOH}$. Figure 6 shows the relationship between time 


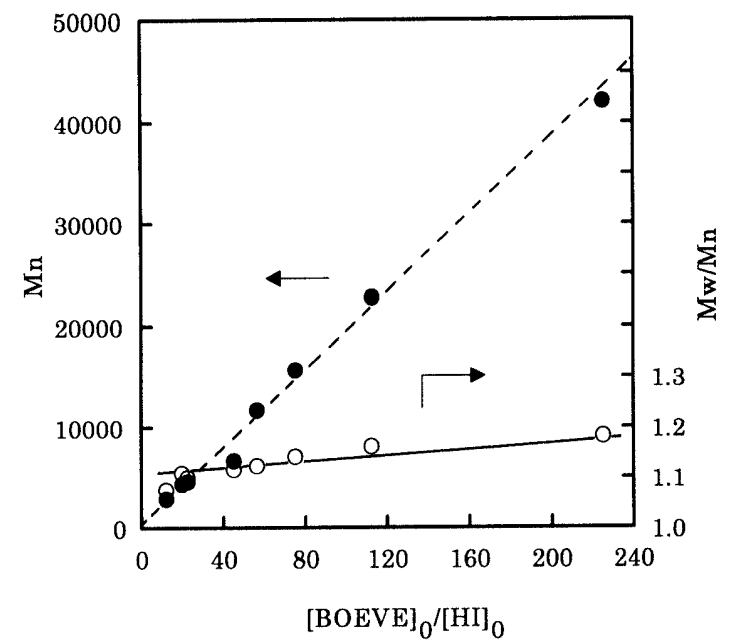

Fig. 5. $M_{n}$ and Its $M_{w} / M_{n}$ Values of Poly(BOEVE) Obtained with the $\mathrm{HI} / \mathrm{ZnI}_{2}$ in Toluene at $-15^{\circ} \mathrm{C}$ as a Function of the Feed Ratio of BOEVE to HI

$[\mathrm{BOEVE}]_{0}=0.18 \mathrm{M} ;\left[\mathrm{ZnI}_{2}\right]=1 \mathrm{mM} ;[\mathrm{HI}]_{0}=0.8-15 \mathrm{~mm}$. Conversion $=100 \%$.

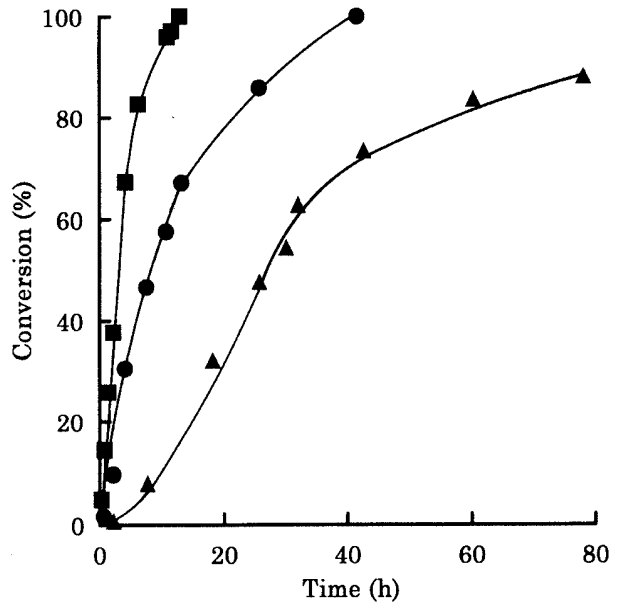

Fig. 6. Relationship between Time and Conversion of Hydrolysis for Poly(BOEVE) and BOEVE in $40 \%$ Dioxane at $37^{\circ} \mathrm{C}$

[A], ester concentration $=0.1 \mathrm{~mm}$. $\mathrm{NaOH}=2.0 \mathrm{~mm}$. $\mathbf{a}$, BOEVE; $\bullet$, poly(BOEVE) $M_{n} \fallingdotseq 1000 ; \boldsymbol{\Lambda}$, poly (BOEVE) $M_{n} \fallingdotseq 2500$

and conversion of hydrolysis for the polymers with $c a$. $1000\left(\mathrm{M}_{\mathrm{w}} / \mathrm{M}_{\mathrm{n}}=1.12\right)$ and $c a .2500\left(\mathrm{M}_{\mathrm{w}} / \mathrm{M}_{\mathrm{n}}=1.11\right)$ of the $\mathrm{M}_{\mathrm{n}}$ and for the BOEVE as control. The progress of the hydrolysis decreased with an increase in the $\mathrm{M}_{\mathrm{n}}$. The polymer with $c a .2500$ of the $\mathrm{M}_{\mathrm{n}}$ was depicted as an Stype curve because it easily became soluble in the media during the progress of hydrolysis. ${ }^{9)}$

The rate of alkaline hydrolysis for the ester group is expressed as Eq. (1),

$$
\frac{\mathrm{d} x}{\mathrm{~d} t}=k(\mathrm{a}-x)(\mathrm{b}-x)
$$

where $\mathrm{a}$ and $\mathrm{b}$ are the initial concentration of the ester and hydroxide ion, respectively. $x$ is the concentration of benzoic acid at time $t . k$ is the apparent reaction rate constant.

Equation (1) was applied to the hydrolysis of BOEVE and poly(BOEVE), and the rate was then investigated. The $\mathrm{d} x / \mathrm{d} t$ was determined by differentiating the curves of Fig. 6. Figure 7 shows the relationship between the

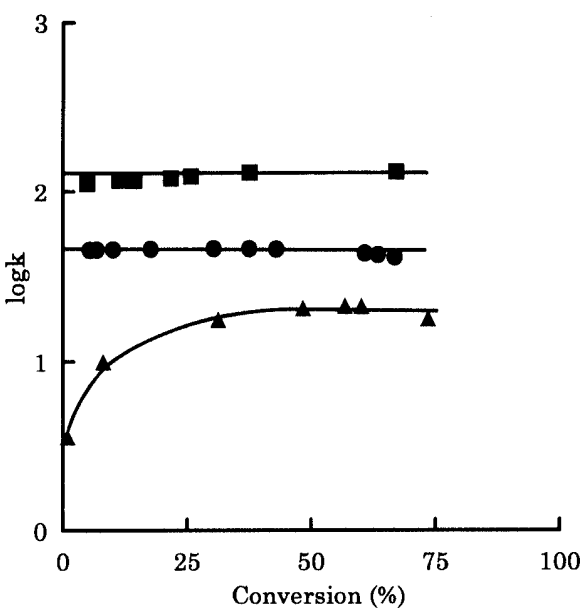

Fig.7. Relationship between Conversion and Rate Constants of Hydrolysis for Poly(BOEVE) and BOEVE in $40 \%$ Dioxane at $37^{\circ} \mathrm{C}$

$[A]$, ester concentration $=0.1 \mathrm{~mm}$. $\mathrm{NaOH}=2.0 \mathrm{~mm}$. $\mathbf{a}$, BOEVE; $\bullet$, poly(BOEVE) $\mathrm{M}_{\mathrm{n}} \fallingdotseq 1000$; $\boldsymbol{\Delta}$, poly(BOEVE) $\mathrm{M}_{\mathrm{n}} \fallingdotseq 2500$.

Table 1. $k_{\text {app }}$ of BOEVE and Poly(BOEVE) in $2 \mathrm{~mm} \mathrm{NaOH}$ Dioxane-Water Media

\begin{tabular}{cccc}
\hline \hline & \multicolumn{3}{c}{$k_{\text {app }}\left(\mathrm{dm}^{3} \cdot \mathrm{mol}^{-1} \cdot \mathrm{h}^{-1}\right)$} \\
\cline { 2 - 4 } Dioxane (\%) & BOEVE & $\begin{array}{c}\text { Poly }(\mathrm{BOEVE}) \\
\left(\mathrm{M}_{\mathrm{n}} \fallingdotseq 1000\right)\end{array}$ & $\begin{array}{c}\text { Poly(BOEVE) } \\
\left(\mathrm{M}_{\mathrm{n}} \fallingdotseq 2500\right)\end{array}$ \\
\hline 20 & 150 & 32 & - \\
30 & 135 & 37 & - \\
40 & 128 & 45 & 21 \\
50 & 107 & 86 & 35 \\
\hline
\end{tabular}

degree of hydrolysis and the $k$ of the poly(BOEVE) or the BOEVE. The $k$ of BOEVE and poly(BOEVE) with $c a$. 1000 of the $M_{n}$ are scarcely affected by the degree of hydrolysis and are kept constant; but that of polymer with $c a .2500$ of the $M_{n}$ was dependent on the degree of hydrolysis. Where the degree of hydrolysis was increased beyond $c a$. $50 \%$, the $k$ became constant and was approximately 45 times larger than the initial $k$. This accelerating effect may be based on increase of the local concentration of alkali due to attraction by free hydroxyl groups of the polymer formed by the hydrolysis. ${ }^{9)}$ In the case of the polymer with $c a .2500$ of the $\mathrm{M}_{\mathrm{n}}$, the hydrolysis reaction seems to be autocatalytic.

To compare $k$ with the difference in molecular weight, the constant values of $k\left(k_{\text {app }}\right)$ obtained from Fig. 7 are shown in Table 1. The effect of the $k_{\mathrm{app}}$ on the other proportions of dioxane-water media is also shown. $k_{\text {app }}$ decreased when the molecular weight was increased; that for BOEVE decreased with an increased proportion of dioxane in the media, while that for the poly(BOEVE) increased. Since the dielectric constant of dioxane is far less than that of water, the dielectric constant of the media decreased when the proportion of dioxane in the media was increased. Poly(BOEVE) is insoluble in water and its affinity for the media decreased with a decrease in the proportion of dioxane. Consequently, the hydrolysis of poly(BOEVE) was found to be influenced by its affinity for the media but that of BOEVE was only affected by 
the dielectric constant of the media.

In conclusion, the cationic polymerization of BOEVE with the $\mathrm{HI} / \mathrm{ZnI}_{2}$ initiating system in toluene at $-15^{\circ} \mathrm{C}$ yielded a living polymer with a narrow MWD. Hydrolysis of the polymer in dioxane-water media became difficult with the increasing $M_{n}$ of the polymer.

\section{Experimental}

The IR spectra were recorded on a JASCO IR Report-810 spectrophotometer and the NMR spectra taken on a JNM-GSX400 FT NMR. The NMR sample solutions were prepared in $\mathrm{CDCl}_{3}$ with a small amount of tetramethylsilane as an internal reference. Elemental analyses were performed at the Analytical Center, College of Science and Technology, Nihon University. The MWD ${ }^{10,11)}$ and $M_{n}$ for the polymers were determined by gel permeation chromatography using a high performance liquid chromatography column (Asahipak GF-7M HQ, Asahi Chemical Industry, Co., Ltd.) at $25^{\circ} \mathrm{C}$ with chloroform as the mobile phase on the basis of a polystyrene calibration.

Materials Toluene and diethyl ether were distilled after dehydration over calcium hydride before use. 1,4-Dioxane was purified by refluxing with sodium and then distilled. 2-Chloroethyl vinyl ether (CEVE, Tokyo Chemical Industry Co., Ltd.), $\mathrm{ZnI}_{2}$ (Wako Pure Chemical Industries, Ltd., purity $>99.5 \%$ ) and $\mathrm{I}_{2}$ (Wako, purity $99.9 \%$ ) were used as received. All other chemicals were of reagent grade. HI was obtained from a $57 \%$ aqueous solution (Wako) by dehydration with phosphorus pentaoxide and stored as a toluene solution. ${ }^{4}$ The concentration of $\mathrm{HI}$ in the stock solution was determined by titration just before use. BOEVE was prepared by the reaction of CEVE with sodium benzoate in the presence of tetra- $n$-butylammonium iodide as the phase-transfer catalyst ${ }^{12,13)}$ and purified twice by distillation under reduced pressure over calcium hydride before use. BOEVE was identified by IR, ${ }^{1} \mathrm{H}$ - and ${ }^{13} \mathrm{C}-\mathrm{NMR}$ spectroscopy: IR (film) $\mathrm{cm}^{-1}: 1619(\mathrm{C}=\mathrm{C}), 1722(\mathrm{C}=\mathrm{O}) .{ }^{1} \mathrm{H}-\mathrm{NMR}$ $\left(\mathrm{CDCl}_{3}\right) \delta 4.01$ and $4.55\left(4 \mathrm{H}, \mathrm{t}, \mathrm{OCH}_{2} \mathrm{CH}_{2} \mathrm{O}\right), 4.05$ and $4.24(2 \mathrm{H}, \mathrm{t}$, $\left.\mathrm{CH}_{2}=\right), 6.51(1 \mathrm{H}, \mathrm{q},-\mathrm{CH}=), 7.40-7.56(3 \mathrm{H}, \mathrm{m}, \mathrm{Ar}), 8.06(2 \mathrm{H}, \mathrm{d}, \mathrm{Ar})$. ${ }^{13} \mathrm{C}$-NMR: 63.05 and $65.55\left(\mathrm{OCH}_{2} \mathrm{CH}_{2} \mathrm{O}\right), 86.97\left(\mathrm{CH}_{2}=\right), 128.24(2 \mathrm{C}$, Ar), $129.60(2 \mathrm{C}, \mathrm{Ar}), 129.80(\mathrm{Ar}), 132.96(\mathrm{Ar}), 151.41(-\mathrm{CH}=), 166.30$ (CO). Anal. Calcd for $\mathrm{C}_{11} \mathrm{H}_{12} \mathrm{O}_{3}: \mathrm{C}, 68.73 ; \mathrm{H}, 6.29$. Found: $\mathrm{C}, 69.07$; H, 6.61 .

Polymerization of BOEVE Cationic polymerization of BOEVE was carried out in a $25 \mathrm{ml}$ baked glass tube equipped with a three-way stopcock under a dry nitrogen atmosphere at $-15^{\circ} \mathrm{C}$. The reaction was initiated by the sequential addition of BOEVE (in toluene), HI (in toluene), and $\mathrm{ZnI}_{2}$ (in diethyl ether) or $\mathrm{I}_{2}$ (in toluene) solutions using a dry syringe and quenched with pre-chilled ammoniacal methanol. Monomer conversion was determined from its residual concentration measured by HPLC with benzyl alcohol as an internal standard. The quenched reaction mixture was extracted with $10 \%$ aqueous sodium thiosulfate, washed with deionized water to remove the initiator residues, and then evaporated to dryness to obtain the polymer. Poly(BOEVE) was identified by IR, ${ }^{1} \mathrm{H}$ - and ${ }^{13} \mathrm{C}$-NMR spectroscopy: IR $(\mathrm{KBr}) \mathrm{cm}^{-1}$ : $1640(\mathrm{C}=\mathrm{O}) .{ }^{1} \mathrm{H}-\mathrm{NMR}\left(\mathrm{CDCl}_{3}\right) \delta 1.65$ and $1.85\left(2 \mathrm{H}, \mathrm{br}, \mathrm{CH}_{2}\right), 3.61$ and $4.31\left(4 \mathrm{H}, \mathrm{br}, \mathrm{CH}_{2} \mathrm{OCH}_{2}\right), 3.66(1 \mathrm{H}, \mathrm{br}, \mathrm{CH}), 7.36-8.05(5 \mathrm{H}, \mathrm{br}$, Ar). ${ }^{13} \mathrm{C}$-NMR: $39.9(\mathrm{CH}), 64.2$ and $66.5\left(\mathrm{OCH}_{2} \mathrm{CH}_{2} \mathrm{O}\right), 73.9\left(\mathrm{CH}_{2}\right)$, 128.3 (2C, Ar), 129.7 (2C, Ar), 130.2 (Ar), 133.0 (Ar), 166.3 (CO).

Hydrolysis The poly(BOEVE) or BOEVE was dissolved in $2 \mathrm{~mm}$ $\mathrm{NaOH}$ dioxane-water media and thermostated at $37^{\circ} \mathrm{C}$. The concentration of the solution was prepared at $0.1 \mathrm{~mm}$ based on the ester group in the solutes. The degree of hydrolysis was determined to measure the resulting concentration of benzoic acid by HPLC.

\section{References}

1) Maeda H., Ueda M., Morinaga T., Matsumoto T., J. Med. Chem., 28, 455-461 (1985).

2) Yokoyama M., Okano M., Sakurai Y., Kataoka T., Drug Delivery System, 6, 77-81 (1991)

3) Ouchi T., Fujino A., Tanaka K., Banba T., J. Controlled Release, 12, 143-153 (1990).

4) Miyamoto M., Sawamoto M., Higashimura T., Macromolecules, 17, 265-268 (1984).

5) Higashimura T., Aoshima S., Sawamoto M., Makromol. Chem., Macromol. Symp., 3, 99-111 (1986).

6) Sawamoto M., Okamoto C.,Higashimura T., Macromolecules, 20 , 2693-2697 (1987).

7) Kojima K., Sawamoto M., Higashimura T., Macromolecules, 22, 1552-1557 (1989).

8) Aoshima S., Nakamura T., Sawamoto M., Higashimura T., Polym. Prepr., Jpn., 34, 169 (1985).

9) Sakurada I., Kobunshi, 17, 21-26 (1968).

10) Cazes J., J. Chem. Educ., 43, A625-626 (1966).

11) Gallot-Grubisic Z., Rempp P., Benoit H., J. Polym. Sci., Polym. Lett. Ed., 5, 753-759 (1967).

12) Aoshima S., Nakamura T., Uesugi N., Sawamoto M., Higashimura T., Macromolecules, 18, 2097-2101 (1985).

13) Sawamoto M., Enoki T., Higashimura T., Polym. Bull., 16, $117-123(1986)$. 